\title{
Fingolimod-associated PML with mild IRIS in MS
}

\author{
A clinicopathologic study \\ OPEN
}

Shuhei Nishiyama, MD,

$\mathrm{PhD}^{*}$

Tatsuro Misu, MD,

$\mathrm{PhD}^{*}$

Yukiko Shishido-Hara,

$\mathrm{MD}, \mathrm{PhD}^{*}$

Kazuo Nakamichi, PhD

Masayuki Saijo, MD,

$\mathrm{PhD}$

Yoshiki Takai, MD, PhD

Kentarou Takei, MD

Naoki Yamamoto, MD

Hiroshi Kuroda, MD,

$\mathrm{PhD}$

Ryuta Saito, MD, PhD

Mika Watanabe, MD,

$\mathrm{PhD}$

Teiji Tominaga, MD,

$\mathrm{PhD}$

Ichiro Nakashima, MD, $\mathrm{PhD}$

Kazuo Fujihara, MD,

$\mathrm{PhD}$

Masashi Aoki, MD, PhD

Correspondence to

Dr. Misu:

misu@med.tohoku.ac.jp

\section{ABSTRACT}

Objective: To clarify the clinical, neuropathologic, and virologic characteristics of progressive multifocal leukoencephalopathy (PML) and its immune reconstitution inflammatory syndrome (IRIS) in a patient with fingolimod-treated MS.

Methods: A case study.

Results: A 34-year-old patient with MS using fingolimod for 4 years had a gradual progression of right hemiparesis and aphasia with a new subcortical white matter lesion in the precentral gyrus by initial MRI. Blood tests were normal, except for lymphopenia (160 cells/ $\mu \mathrm{L})$. One month after the cessation of fingolimod, brain MRI depicted a diffusely exacerbated hyperintensity on fluid-attenuated inversion recovery and diffusion-weighed imaging in the white matter with punctate gadolinium enhancement, suggesting PML-IRIS. A very low level of JC virus (JCV)-DNA (15 copies $/ \mathrm{mL}$ ) was detected in the CSF as judged by quantitative PCR. Brain tissues were biopsied from the left frontal lesion, which showed some small demyelinated foci with predominant loss of myelin-associated glycoprotein with infiltrations of lymphocytes and macrophages, but clear viral inclusion was not observed with hematoxylineosin staining. JCV-DNA was uniquely detectable in an active inflammatory demyelinating lesion by in situ hybridization, possibly suggesting an early phase of PML. DNA extracted from the brain sample was positive for JCV-DNA (151 copies/cell). It took 3 months to normalize the blood lymphocyte count. The patient was treated with $1 \mathrm{~g}$ of IV methylprednisolone for 3 days and a weekly oral dose (375 mg) of mefloquine, and her symptoms gradually improved.

Conclusion: Low CSF JCV-DNA and unfound viral inclusions initially made her diagnosis difficult. The clinical course of fingolimod-associated PML may be associated with mild immune reconstitution. Neurol Neuroimmunol Neuroinflamm 2018;5:e415; doi: 10.1212/NXI.0000000000000415

\section{GLOSSARY}

DMT = disease-modifying treatment; DWI = diffusion-weighted imaging; FLAIR = fluid-attenuated inversion recovery; IRIS = immune reconstitution inflammatory syndrome; JCV = JC virus; $\mathbf{M A G}=$ myelin-associated glycoprotein; $\mathbf{M B P}=$ myelin basic protein; PML = progressive multifocal leukoencephalopathy; RRMS = relapsing-remitting MS.

Fingolimod is an oral disease-modifying drug approved for relapsing-remitting MS (RRMS), which downregulates the sphingosine-1-phosphate receptor and subsequently prevents lymphocyte egress from lymph nodes. ${ }^{1}$ Until now, 13 cases of fingolimod-associated progressive multifocal leukoencephalopathy (PML) including this case have been reported in patients with RRMS (personal oral communication, Mitsubishi Tanabe Pharma, 2017); ${ }^{2,3}$ however, there has been no report of immune reconstitution inflammatory syndrome (IRIS). We herein report a case of fingolimod-associated PML accompanied by IRIS with favorable clinical course, which showed early pathologic changes of PML-IRIS in a biopsied specimen.

*These authors contributed equally to the manuscript.

From the Department of Neurology (S.N., T.M., Y.T., K.T., N.Y., H.K., M.A.), Department of Multiple Sclerosis Therapeutics (T.M.), Department of Neurosurgery (R.S., T.T.), and Department of Pathology (M.W.), Tohoku University Graduate School of Medicine, Sendai; Department of Anatomic Pathology (Y.S.-H.), Tokyo Medical University; Department of Virology 1 (K.N., M.S.), Laboratory of Neurovirology, National Institute of Infectious Diseases; Department of Neurology (I.N.), Tohoku Medical and Pharmaceutical University, Sendai; and Department of Multiple Sclerosis Therapeutics (K.F.), Fukushima Medical University School of Medicine and Multiple Sclerosis and Neuromyelitis Optica Center, Southern TOHOKU Research Institute for Neuroscience, Japan.

Funding information and disclosures are provided at the end of the article. Go to Neurology.org/nn for full disclosure forms. The Article Processing Charge was funded by JSPS KAKENHI.

This is an open access article distributed under the terms of the Creative Commons Attribution-NonCommercial-NoDerivatives License 4.0 (CC BY-NC-ND), which permits downloading and sharing the work provided it is properly cited. The work cannot be changed in any way or used commercially without permission from the journal. 
CASE A 34-year-old woman was diagnosed as having RRMS with typical MRI lesions, the so-called Dawson fingers, when she had experienced the initial mild symptoms of paresthesia and dysphagia at the age of 14 years. During 11 years treated with interferon$\beta 1 \mathrm{~b}$, she had $12 \mathrm{MS}$ relapses. She had no history of immunosuppressive treatment. At the age of 30 with an Expanded Disability Status Scale score of 6.0, her treatment was changed to fingolimod, and she had no further relapse and disability worsening, although the $\mathrm{JC}$ virus (JCV)-antibody was positive (Index 1.13).

Early in January, she noticed gradually aggravating muscle weakness of the right hand, dysarthria, and hemiparetic gait. She visited our clinic by lateMarch, and she discontinued fingolimod treatment because of lymphopenia (160 cells/ $\mu \mathrm{L})$.

She was admitted to our hospital by mid-April. Initial brain MRI on admission showed fluidattenuated inversion recovery (FLAIR)-high signal lesions sharply delineated toward the cortex and consecutive deep white matter with hyperintense diffusion-weighted imaging (DWI) signals in the left frontoparietal region (figure 1, A and B). There was no mass effect and no gadolinium enhancement in any lesions (figure 1C). All blood tests including biochemistry and blood cell counts were normal, except for lymphopenia (442 cells/ $\mu \mathrm{L})$. CSF examination showed no cells, elevated protein concentration $(81$ $\mathrm{mg} / \mathrm{dL}$ ), elevated $\operatorname{IgG}$ index (0.89), and positive oligoclonal IgG bands.

\section{Figure 1 Brain MRI findings in the present case}

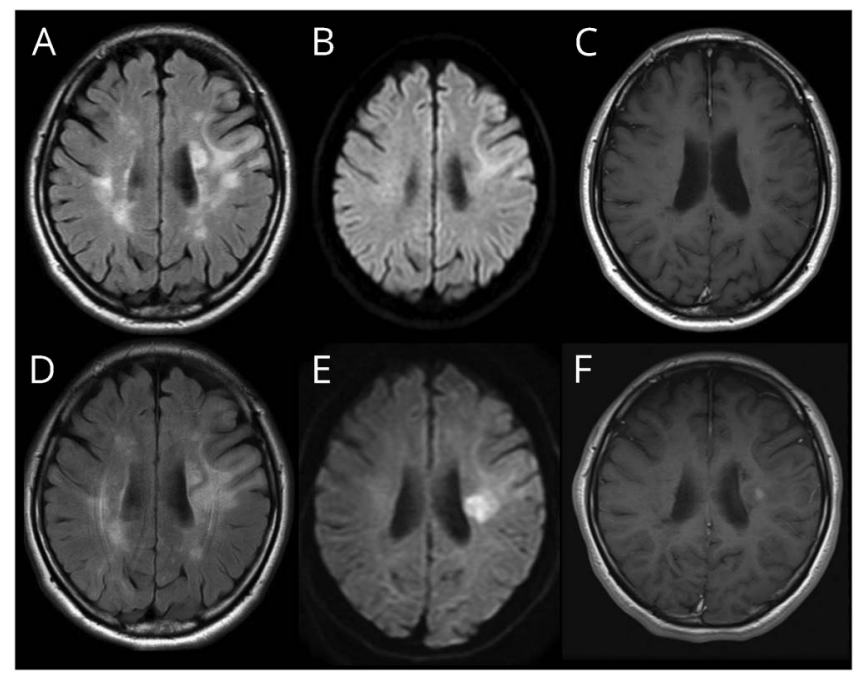

( $A$ and $D$ ) Fluid-attenuated inversion recovery (FLAIR), (B and E) diffusion-weighted imaging (DWI), (C and F) gadolinium-enhanced T1-weighted imaging. (A-C) Initial brain MRI on admission showed FLAIR-high lesion sharply delineated toward the precentral gyrus cortex with hyperintense-DWI signal. There was no gadolinium-enhanced lesion at that time. (D-F) Secondary brain MRI a month after admission showed a widely spread periventricular lesion with spotty gadolinium enhancement. These lesions indicate immune reconstruction inflammatory syndrome (IRIS).
One month after admission with gradually worsening aphasia and right hemiplegia, secondary brain MRI revealed several enlarged lesions (figure 1, D and E) with gadolinium enhancement in T1weighted hypointensity (figure 1F), showing a punctate pattern. ${ }^{4} \mathrm{~A}$ very low level of CSF-JCV-DNA was detected in the CSF by quantitative PCR (15 copies/ $\mathrm{mL}$ ) when examined at the National Institute of Infectious Diseases (Tokyo, Japan). In mid-June, the patient was treated with $1 \mathrm{~g}$ of IV methylprednisolone for 3 days and oral mefloquine $(375 \mathrm{mg} / \mathrm{wk}$ ) for 6 months. Two months after the treatment, CSFJCV became negative, and the blood lymphocyte count was normalized. Her aphasia and right hemiplegia gradually improved.

RESULTS OF PATHOLOGICAL STUDY In lateMay, stereotactic needle brain biopsy was performed after written informed consent was obtained. Seven tissue fragments ( $1 \mathrm{~mm}$ in width and $2-5 \mathrm{~mm}$ in length) were obtained from the left frontal lobe (figure 2A). With hematoxylin-eosin staining, proliferation of small round cells was apparent, including glial cells and inflammatory components such as lymphocytes, plasma cells, and macrophages. Typical JCV-infected oligodendroglia presenting viral inclusions in the markedly enlarged nuclei were hardly seen. In all fragments of biopsied tissue, CD68positive cells were scattered, and there were some aggregations of CD68-positive cells (figure $2 \mathrm{~B}$, circled). In these lesions, there were multifocal subacute (figure 2, C-E) and acute (figure 2, F-L) demyelinating oval lesions with loss of myelin-associated glycoprotein (MAG) (figure 2, C and G). In subacute lesions without viral inclusion (figure 2, C-E), the immunoreactivity against myelin basic protein (MBP) was partially lost (figure 2D), whereas CD8positive lymphocytes were observed only at the periphery (figure 2E), suggesting PML-like MAGdominant demyelinated lesions.

In acute demyelinating lesions, oligodendroglialike cells with medium-sized nuclei were present with clustered inflammatory cells (red yellow arrow in figure $2 \mathrm{~F}$ ). Their nuclei were smaller than typical JCV-infected oligodendroglia, known as a diagnostic hallmark of PML, but mildly enlarged over lymphocytic nuclei. These cells were negative for glial fibrillary acidic protein or lymphocytic markers, and many of them showed intranuclear structures in dots, suggesting JCV-infected oligodendroglia in the early stage of viral infection. Moreover, a cell with relatively large irregular nucleus resembling a JCV-infected astrocyte was also present (yellow arrow in figure 2F). This lesion was in the active demyelinating phase with loss of MAG but completely preserved MBP infiltrated with $\mathrm{CD}^{-}$, $\mathrm{CD}^{-}$, and $\mathrm{CD} 79 \mathrm{a}^{-}$ 

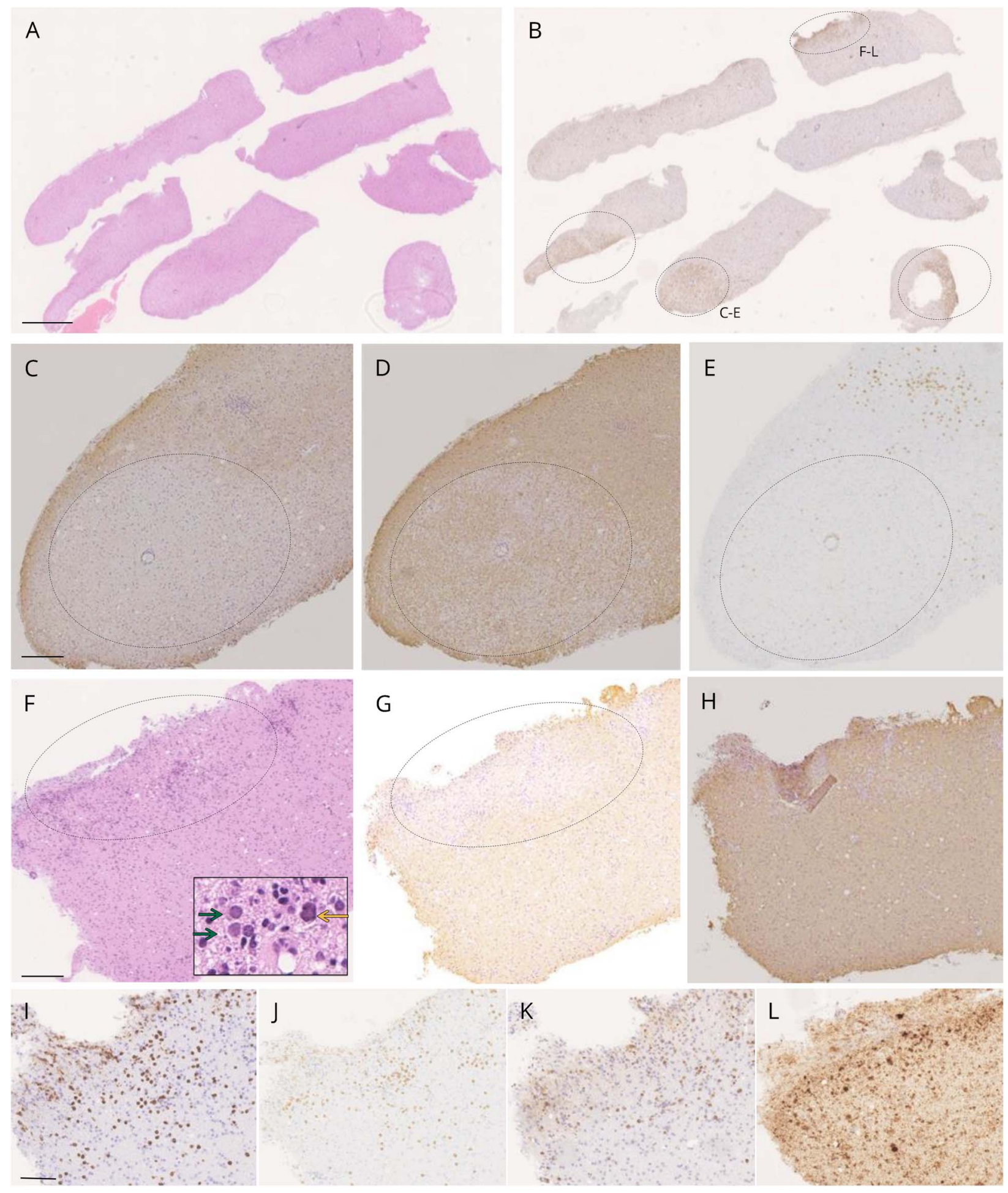

(A) Fragments of biopsied brain tissues (hematoxylin-eosin: HE staining). Affected lesions were obscure with HE staining. A and B are serial sections (scale bar: $500 \mathrm{~mm}$ ). (B) Although demyelinated lesions were not clear with Kluver-Barrera staining, there were 4 demyelinating areas with high density of CD68 cells lacking myelin-associated glycoprotein (MAG) or myelin basic protein (MBP). Two of them were relatively in subacute (C-E) and acute phases (F-L). (C) In typical oval demyelinating lesion with massive macrophage infiltration, there was a lesion with dominant loss of MAG compared with partially lacked MBP (D) with CD8-positive cells at the periphery $(E)$, suggesting a subacute demyelinated lesion with distal oligodendrogliopathy. C-E is a serial section (scale bar: $200 \mu \mathrm{m})$. (F) In another active inflammatory lesion (HE staining), there were massive infiltrations of macrophages and lymphocytes diffusely in demyelinating lesions. In these lesions, oligodendroglia-like cells with mildly enlarged nuclei were present (green arrows). An astroglia-like cell suspicious for JC virus (JCV) infection was also seen (yellow arrow). Within serial sections of $F$, loss of MAG was present (G) with completely preservation of MBP (H), suggesting in acute phase. F-H is a serial section (scale bar: $200 \mu \mathrm{m}$ ). (I-L) Properties of inflammatory cells (l: CD3, J: CD8, and K: CD79a). There were numerous CD3 ${ }^{+}$T cells and $\mathrm{CD79} \mathrm{a}^{+} \mathrm{B}$ cells and plasma cells, and both helper and cytotoxic T cells were present in an almost equal ratio, where JCV-infected cells were observed (L: in situ hybridization (ISH) VP1). I-L is a serial section (scale bar: $50 \mu \mathrm{m}$ ). PML = progressive multifocal leukoencephalopathy. 
positive cells (figure $2, \mathrm{G}-\mathrm{I}$ ), suggesting a very active inflammatory lesion, where several JCV-infected cells were uniquely observed (figure 2L).

Oligodendroglia-like cells with dot-shaped inclusions were seen in the lesions (figure 3, A and B), reflecting JCV proliferation in promyelocytic leukemia nuclear bodies. ${ }^{5}$ Immunohistological examination of JCV capsid proteins or agnoprotein revealed only a few cells (figure 3C). In situ hybridization for JCV genomic DNA detected at least $7 \mathrm{JCV}$-positive cells (figure 3D) with definite high-intense nuclear signals, confirming JCV infection. The distribution of JCV-positive cells was associated with active inflammatory lesions showing the infiltration of helper and cytotoxic $\mathrm{T}$ cells, suggesting a mild host inflammatory response against JCV.

The quantitative real-time PCR examination targeting the JCV large $\mathrm{T}$ gene was repeatedly performed in CSF (figure 3E) and brain samples (figure 3F). ${ }^{6}$ The PCR testing of brain tissue revealed the presence of JCV-DNA (151 copies/cell) (figure $3 \mathrm{~F}$ ). These results indicated that the biopsied brain lesions represented PML pathology, but not MS. The viral titer was markedly low, and nuclear features of oligodendroglia indicated an early stage of JCV infection. Small inflammatory foci may suggest mild host responses against JCV infection, consistent with fingolimod-associated PML-IRIS.

DISCUSSION The clinical and pathologic diagnosis of PML-IRIS is challenging, particularly when the consequence of JCV reactivation and immune reconstitution is not clear. ${ }^{3}$ PML is essentially rare in patients with fingolimod-associated MS without other previous immunosuppressive treatments. The low CSF viral load and the presence of markedly few JCV-positive cells have raised the matter of difficulty in PML diagnosis in the present study. Clinical worsening was accelerated after the cessation of fingolimod with punctate gadolinium enhancement in MRI, suggesting PML-IRIS. Pathologic examination of biopsied brain tissue revealed some JCV-DNA-positive cells only in an active demyelinating lesion dominantly lacking $\mathrm{MAG}^{7}$ and JCV-infected glial cells with dot-shaped

Figure 3 Detection of JC virus (JCV) genomic DNA in mildly enlarged nuclei of oligodendroglia-like cells
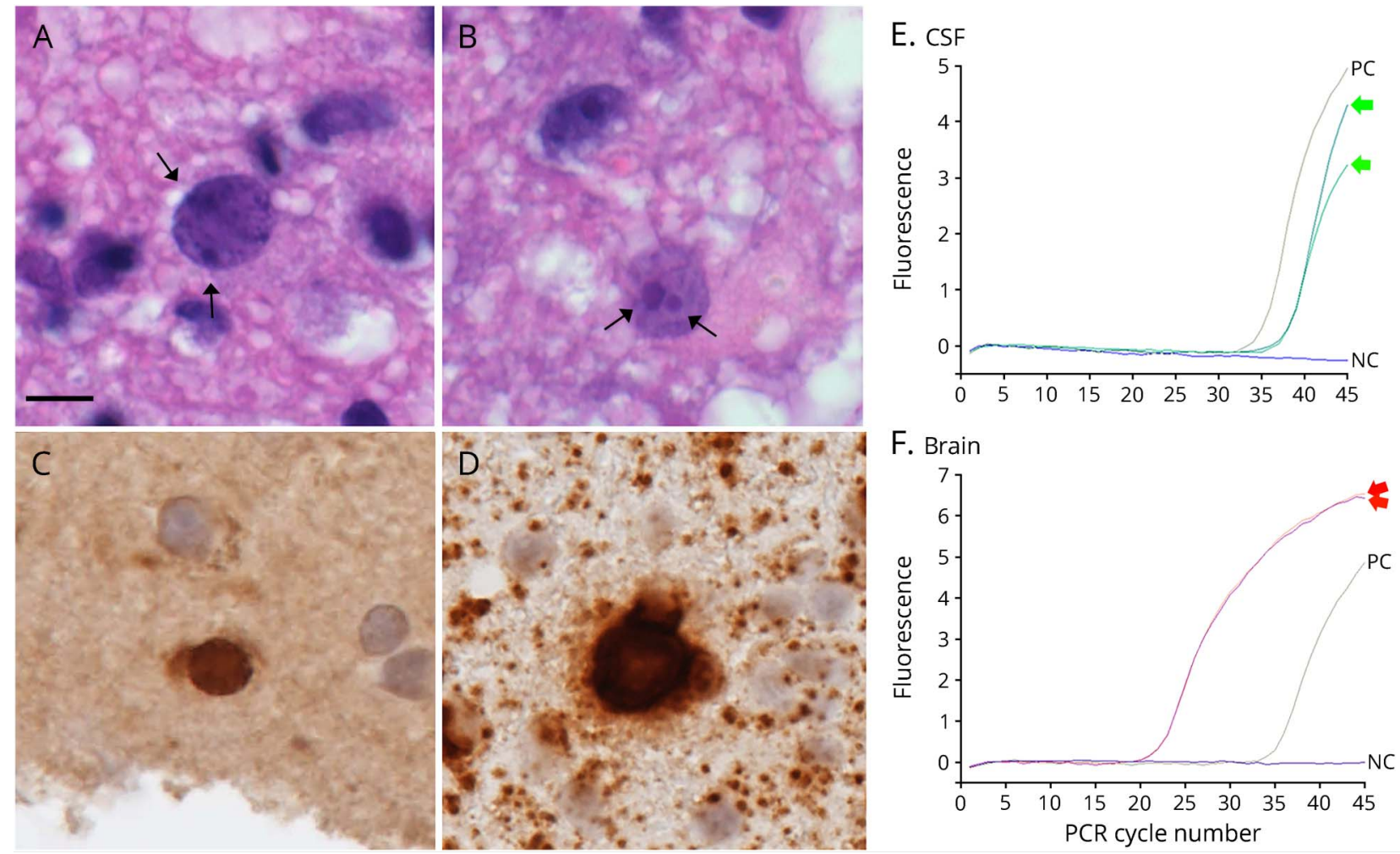

(A and B) Oligodendroglia-like cells with dot-shaped inclusions (hematoxylin-eosin). Dot-shaped inclusions were seen at the inner nuclear periphery in A (arrows), and large and small punctuated structures were present in B (arrows). (C) Immunohistochemistry against JCV capsid protein (VP2/VP3C antibody). There was only one cell suspicious for immunoreactivity against JCV capsid protein, but apparently positive cells were hardly detectable for agnoprotein. (D) In situ hybridization (ISH) for JCV genomic DNA. Sensitive ISH detected 7 oligodendroglia-like cells with JCV genomic DNA in the mildly enlarged nuclei. A-D is a serial section (scale bar: $10 \mu \mathrm{m}$ ). (E and F) PCR detection of JCV genomic DNA. DNA was extracted from either CSF specimen (E) or biopsied brain tissues $(F)$, and the JCV-DNA copy number in each sample was determined by a quantitative PCR targeting the JCV large T gene. NC = negative control (no PCR template); PC = Positive control (approximately 100 copies/reaction). PCR were performed in duplicate (green arrows in E and red arrows in F). 
inclusions surrounded by inflammatory cells, suggesting an early phase of PML in association with immune reconstitution. The pathologic features in fingolimod-associated PML in MS may include only early and weak characteristic features with immunoreaction, differing from previously reported PML by other disease-modifying treatments (DMTs) such as natalizumab, an anti- $\alpha 4$-integrin monoclonal antibody.

The rarity of fingolimod-associated PML-IRIS may be related to its different mechanisms compared with other DMT. In natalizumab, most PML cases had been treated with plasmapheresis causing early IRIS with a high mortality rate and poor prognosis. ${ }^{8}$ Therefore, urgent removal of drug efficacy might be associated with acceleration of lymphocyte infiltration causing IRIS. By contrast, in fingolimod, lymphopenia was reported in previous PML cases, but the kinetics of immune reconstitution in patients with MS was varied from half to several months, ${ }^{2,9}$ which might have impacts on the occurrence of PMLIRIS. Other possible reasons of rarity in fingolimodassociated PML-IRIS may be the lack of pathologic studies and the relatively mild clinical symptom, causing underestimation.

Because of weak pathologic changes in brain tissue and an extremely low JCV-DNA level in CSF, MRI was the most useful and sensitive technique used to detect PML and PML-IRIS in the present case, showing DWI-high and FLAIR-high signals like previous PML cases. ${ }^{10}$

\section{AUTHOR CONTRIBUTIONS}

Shuhei Nishiyama: study conception; acquisition, analysis, and interpretation of data for the work; and writing of the manuscript. Tatsuro Misu: substantial contribution to the study conception and design of the work; writing and revising manuscripts; and supervision of the acquisition, analysis, and interpretation of data for the work. Yukiko Shishido-Hara: substantial contribution to the design of the work; writing of the manuscript; and supervision of the acquisition, analysis, and interpretation of data for the work. Kazuo Nakamichi: study conception and design of the work and supervision of the acquisition, analysis, and interpretation of data for the work. Masayuki Saijo: supervision of the acquisition and interpretation of data for the work. Yoshiki Takai: analysis, acquisition, and interpretation of data for the work. Kentarou Takei, Naoki Yamamoto, Hiroshi Kuroda, and Ryuta Saito: acquisition and interpretation of data for the work. Mika Watanabe: analysis, acquisition, and interpretation of data for the work. Teiji Tominaga, Ichiro Nakashima, Kazuo Fujihara, and Masashi Aoki: supervision of the acquisition and interpretation of data for the work.

\section{STUDY FUNDING}

This work was partly supported by JSPS KAKENHI (Grant Number 26461286, 17K09768, 26293205, 15K09332, and 17H04192), the Research Committee of Prion Disease and Slow Virus Infection Research on Policy Planning and Evaluation for Rare and Intractable Diseases and a Grant-in-Aid for Scientific Research (Neuroimmunological Diseases) from the Ministry of Health, Labor, and Welfare of Japan, and the Research Committee of Molecular Pathogenesis and Therapies for Prion Disease and Slow Virus Infection, the Practical Research Project for Rare/ Intractable Disease from Japan Agency for Medical Research and Development, AMED.

\section{DISCLOSURE}

Shuhei Nishiyama has received Grants-in-Aid for Scientific Research. Tatsuro Misu has received Grants-in-Aid for Scientific Research; has received speaker honoraria from Bayer Schering Pharma, Biogen Idec Japan, and Mitsubishi Tanabe Pharma Corporation; and has received research support from Mitsubishi Tanabe Pharma, Chugai Pharma, The Chemo-Sero-Therapeutic Research Institute, Takeda Pharmaceutical, Asahi Kasei Medical Co., and Cosmic Corporation. Yukiko Shishido-Hara has received Grants-in-Aid for Scientific Research and is on the editorial board for Pathology International. Kazuo Nakamichi has received Grants-in-Aid for Scientific Research. Masayuki Saijo has received Grants-in-Aid for Scientific Research; is Editor-in-Chief for Japanese Journal of Infectious Diseases; and received research support from Japan Agency for Medical Research and Development. Yoshiki Takai has received Grants-in-Aid for Scientific Research. Kentarou Takei and Naoki Yamamoto report no disclosures. Hiroshi Kuroda, Ryuta Saito, Mika Watanabe, and Teiji Tominaga have received Grants-in-Aid for Scientific Research. Ichiro Nakashima has received Grants-in-Aid for Scientific Research; has received funding for travel; received speaker honoraria from Tanabe Mitsubishi Pharma Corporation; has received research funding from LSI Medience Corporation; and is an editorial board for Multiple Sclerosis International. Kazuo Fujihara has received Grants-in-Aid for Scientific Research; serves on scientific advisory boards for Bayer Schering Pharma, Biogen Idec, Mitsubishi Tanabe Pharma Corporation, Novartis Pharma, Chugai Pharmaceutical, Ono Pharmaceutical, Nihon Pharmaceutical, Merck Serono, Alexion Pharmaceuticals, MedImmune, and Medical Review; has received funding for travel and speaker honoraria from Bayer Schering Pharma, Biogen Idec, Eisai Inc., Mitsubishi Tanabe Pharma Corporation, Novartis Pharma, Astellas Pharma Inc., Takeda Pharmaceutical Company Limited, Asahi Kasei Medical Co., Daiichi Sankyo, and Nihon Pharmaceutical; serves as an editorial board member of Clinical and Experimental Neuroimmunology (2009 till present) and an advisory board member of Sri Lanka Journal of Neurology; and has received research support from Bayer Schering Pharma, Biogen Idec Japan, Asahi Kasei Medical, The Chemo-Sero-Therapeutic Research Institute, Teva Pharmaceutical, Mitsubishi Tanabe Pharma, Teijin Pharma, Chugai Pharmaceutical, Ono Pharmaceutical, Nihon Pharmaceutical, and Genzyme Japan. Masashi Aoki has received Grants-in-Aid for Scientific Research. Go to Neurology.org/nn for full disclosure forms.

Received July 25, 2017. Accepted in final form September 26, 2017.

\section{REFERENCES}

1. Chiba K, Yanagawa Y, Masubuchi Y, et al. FTY720, a novel immunosuppressant, induces sequestration of circulating mature lymphocytes by acceleration of lymphocyte homing in rats. I. FTY720 selectively decreases the number of circulating mature lymphocytes by acceleration of lymphocyte homing. J Immunol 1998;160: 5037-5044.

2. Gyang TV, Hamel J, Goodman AD, Gross RA, Samkoff L. Fingolimod-associated PML in a patient with prior immunosuppression. Neurology 2016;86:1843-1845.

3. Bauer J, Gold R, Adams O, Lassmann H. Progressive multifocal leukoencephalopathy and immune reconstitution inflammatory syndrome (IRIS). Acta Neuropathol 2015;130:751-764.

4. Hodel J, Darchis C, Outteryck O, et al. Punctate pattern: a promising imaging marker for the diagnosis of natalizumab-associated PML. Neurology 2016;86:15161523.

5. Shishido-Hara Y. Progressive multifocal leukoencephalopathy and promyelocytic leukemia nuclear bodies: a review of clinical, neuropathological, and virological aspects of JC virus-induced demyelinating disease. Acta Neuropathol 2010;120:403-417.

6. Nakamichi K, Mizusawa H, Yamada M, et al. Characteristics of progressive multifocal leukoencephalopathy 
clarified through internet-assisted laboratory surveillance in Japan. BMC Neurol 2012;12:121.

7. Itoyama Y, Webster HD, Sternberger NH, et al. Distribution of papovavirus, myelin-associated glycoprotein, and myelin basic protein in progressive multifocal leukoencephalopathy lesions. Ann Neurol 1982;11: 396-407.

8. Tan IL, McArthur JC, Clifford DB, Major EO, Nath A. Immune reconstitution inflammatory syndrome in natalizumab-associated PML. Neurology 2011;77: 1061-1067.

9. Johnson TA, Shames I, Keezer M, et al. Reconstitution of circulating lymphocyte counts in FTY720-treated MS patients. Clin Immunol 2010;137:15-20.

10. Yousry TA, Pelletier D, Cadavid D, et al. Magnetic resonance imaging pattern in natalizumab-associated progressive multifocal leukoencephalopathy. Ann Neurol 2012; 72:779-787. 


\section{Neurology \\ Neuroimmunology \& Neuroinflammation}

Fingolimod-associated PML with mild IRIS in MS: A clinicopathologic study

Shuhei Nishiyama, Tatsuro Misu, Yukiko Shishido-Hara, et al.

Neurol Neuroimmunol Neuroinflamm 2018;5;

DOI 10.1212/NXI.0000000000000415

This information is current as of November 10, 2017

\section{Updated Information \& Services}

References

Subspecialty Collections

Permissions \& Licensing

Reprints including high resolution figures, can be found at:

http://nn.neurology.org/content/5/1/e415.full.html

This article cites 10 articles, 1 of which you can access for free at: http://nn.neurology.org/content/5/1/e415.full.html\#\#ref-list-1

This article, along with others on similar topics, appears in the following collection(s):

All Demyelinating disease (CNS)

http://nn.neurology.org//cgi/collection/all_demyelinating_disease_cns MRI

http://nn.neurology.org//cgi/collection/mri

Multiple sclerosis

http://nn.neurology.org//cgi/collection/multiple_sclerosis

Information about reproducing this article in parts (figures,tables) or in its entirety can be found online at:

http://nn.neurology.org/misc/about.xhtml\#permissions

Information about ordering reprints can be found online:

http://nn.neurology.org/misc/addir.xhtml\#reprintsus

Neurol Neuroimmunol Neuroinflamm is an official journal of the American Academy of Neurology.

Published since April 2014, it is an open-access, online-only, continuous publication journal. Copyright

Copyright (C) 2017 The Author(s). Published by Wolters Kluwer Health, Inc. on behalf of the American

Academy of Neurology.. All rights reserved. Online ISSN: 2332-7812.

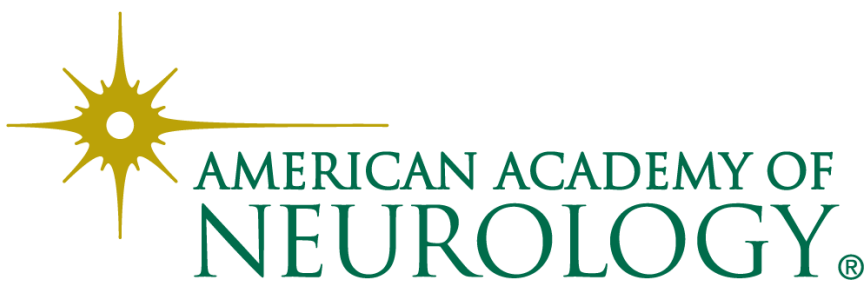

